University of Wollongong

Research Online

Faculty of Social Sciences - Papers (Archive) Faculty of Arts, Social Sciences \& Humanities

2014

Concerns about partner infidelity are a barrier to adoption of HIV-prevention strategies among young South African couples

Lisa Parker

Futures Group

Audrey Pettifor

University of North Carolina

Suzanne Maman

University of North Carolina

Jabu Sibeko

University of The Witwatersrand

Catherine L. Mac Phail

University of Wollongong, cmacphai@uow.edu.au

Follow this and additional works at: https://ro.uow.edu.au/sspapers

Part of the Education Commons, and the Social and Behavioral Sciences Commons

Research Online is the open access institutional repository for the University of Wollongong. For further information contact the UOW Library: research-pubs@uow.edu.au 


\title{
Concerns about partner infidelity are a barrier to adoption of HIV-prevention strategies among young South African couples
}

\author{
Abstract \\ As part of a larger study to examine the feasibility and acceptability of a couples-based HIV-prevention \\ intervention, we conducted formative in-depth interviews with 10 couples to explore topics such as \\ challenges in practising safer sex, HIV-prevention strategies, gender power and violence, and issues of \\ trust and infidelity. In this study, both men and women perceived infidelity as ubiquitous in their social \\ context and were therefore unable to discuss HIV risk and prevention without suspicions of infidelity in \\ their own relationship. This impacted couples' ability openly and effectively to discuss strategies to \\ prevent HIV and thus may have contributed to the limited uptake of HIV-prevention strategies, such as \\ condom use and HIV testing. The contentious nature of safe-sex discussions placed both members of \\ the couple at a higher risk for HIV acquisition within the partnership. This study sheds light on how \\ existing relationship norms in South Africa influence HIV-prevention communication within couples and \\ suggests that new ways of approaching conflictual issues such as mistrust and infidelity are vital in order \\ for HIV-prevention programmes to succeed.

\section{Disciplines} \\ Education | Social and Behavioral Sciences

\section{Publication Details} \\ Parker, L., Pettifor, A., Maman, S., Sibeko, J. \& MacPhail, C. (2014). Concerns about partner infidelity are a \\ barrier to adoption of HIV-prevention strategies among young South African couples. Culture, Health and \\ Sexuality, 16 (7), 792-805.
}




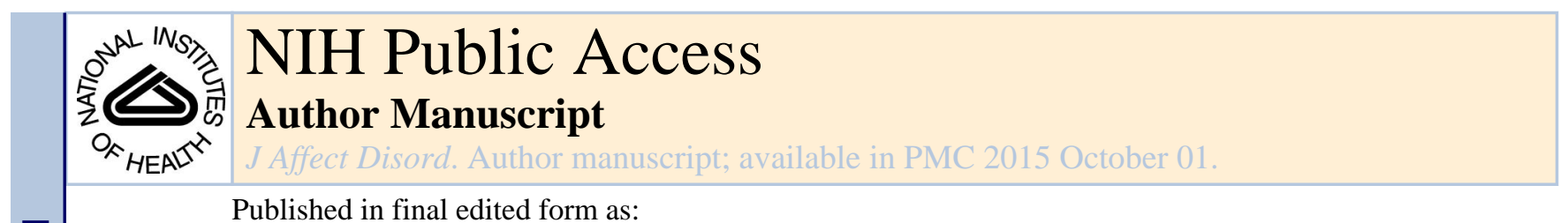

Published in final edited form as:

J Affect Disord. 2014 October ; 167: 160-166. doi:10.1016/j.jad.2014.06.003.

\title{
Validity of the patient health questionnaire-9 to screen for depression in a high-HIV burden primary healthcare clinic in Johannesburg, South Africa
}

\author{
Rushina Cholera, \\ Department of Epidemiology, UNC Gillings School of Global Public Health \\ Bradley Gaynes, \\ Department of Psychiatry, UNC School of Medicine \\ Brian Pence, \\ University of North Carolina Gillings School of Global Public Health, Chapel Hill, NC \\ Jean Bassett, \\ Witkoppen Health and Welfare Center, Johannesburg, South Africa \\ Nandipha Qangule, \\ Witkoppen Health and Welfare Center, Johannesburg, South Africa
}

Catherine Macphail,

Collaborative Research Network for Mental Health and Well-being in Rural Communities, University of New England, Armidale, Australia \& Wits Reproductive Health and HIV Institute, University of the Witwatersrand, Johannesburg, South Africa

Shelley Bernhardt,

Witkoppen Health and Welfare Center, Johannesburg, South Africa

Audrey Pettifor, and

Department of Epidemiology, UNC Gillings School of Global Public Health

William Miller

Department of Medicine, UNC School of Medicine; Department of Epidemiology, UNC Gillings

School of Global Public Health

\footnotetext{
(C) 2014 Elsevier B.V. All rights reserved.

Corresponding author: Rushina Cholera, Department of Epidemiology, University of North Carolina at Chapel Hill, McGavranGreenberg Hall, 135 Dauer Drive, Chapel Hill, NC 27599 USA, rcholera @ med.unc.edu.

Contributors RC designed and managed the study, completed the analysis, and wrote the manuscript with input from WM. BG, BP, and WM gave feedback on study design and analyses. JB and NQ contributed to implementation of the study at the research site and gave advice on study design. SB collected data using the reference standard and contributed to interpretation of the results. AP contributed to interpretation of results. All authors discussed the results and commented on the manuscript. All authors contributed to and have approved the final manuscript.

Conflict of Interest We have no conflicts of interest to report.

Publisher's Disclaimer: This is a PDF file of an unedited manuscript that has been accepted for publication. As a service to our customers we are providing this early version of the manuscript. The manuscript will undergo copyediting, typesetting, and review of the resulting proof before it is published in its final citable form. Please note that during the production process errors may be discovered which could affect the content, and all legal disclaimers that apply to the journal pertain.
} 


\section{Keywords}

Depression; HIV; Validation study; Screening; Africa

\section{INTRODUCTION}

Mental illness imposes an immense global disease burden, particularly in low and middleincome countries where access to mental health services is lacking (Kessler et al., 2009, Becker and Kleinman, 2013). Major depressive disorder (MDD) is the second leading contributor to years lived with disability (YLD) globally, and ranks within the top four causes of YLDs in all regions worldwide (Vos et al., 2012). In sub-Saharan Africa more than two-thirds of patients with severe mental illness are unable to access mental health care and this number rises to approximately $80 \%$ for patients with moderate or mild mental illness (Wang et al., 2007). To address these challenges, the integration of mental health screening approaches in primary care has been suggested as a mode for increasing access to care in low and middle-income settings (Collins et al., 2013, Tomlinson et al., 2009b).

The implementation of routine mental health screening in sub-Saharan African primary health care (PHC) settings requires validated rapid screening instruments that can be easily administered by lay healthcare workers in busy clinics (Freeman et al., 2005, Becker and Kleinman, 2013). To our knowledge, brief depression screening tools have not been validated for a general PHC context in sub-Saharan Africa. A limited number of validation studies of depression screening tools have been conducted against diagnostic reference standards in sub-Saharan African settings, but these studies have varied in their choice of context, screening tool, and diagnostic measure, making the results difficult to apply to a PHC context. (Andersen et al., 2011, Akena et al., 2012a, Akena et al., 2012b, Pence et al., 2012, Chishinga et al., 2011, Monahan et al., 2009, Myer et al., 2008, Nakimuli-Mpungu et al., 2012b, Spies et al., 2009, Adewuya et al., 2006, Akena et al., 2013). In particular, the populations included in these studies, such as university students, household survey participants, pregnant or postnatal women, or HIV-infected patients, are not easily generalizable to a PHC population.

Depression is a common and debilitating comorbidity of HIV in sub-Saharan Africa. The reported prevalence of depression in HIV-infected African adults in ranges from 8-60\%, several times greater than prevalence estimates in the general population (Ramirez-Avila et al., 2012, Hughes et al., 2004, Kagee and Martin, 2010, Myer et al., 2008, Olley et al., 2004, Lawler et al., 2011, Kinyanda et al., 2011, Nakimuli-Mpungu et al., 2011, NakimuliMpungu et al., 2012a, Tomlinson et al., 2009a). The relationship between MDD and HIV is complex, as depression can be a risk factor for HIV acquisition as well as a consequence of HIV infection (Smit et al., 2006, Simoni et al., 2011). However, MDD has long been recognized as a predictor of negative clinical outcomes among people with HIV (Bing et al., 2001, Simoni et al., 2011, Owe-Larsson et al., 2009, Lopes et al., 2012). Persons with depression initiate anti-retroviral treatment (ART) at lower CD4 counts than people without mental illness, and depressed patients are much less likely to adhere to ART than patients 
who are not depressed (Tegger et al., 2008, Gonzalez et al., 2011, Nakimuli-Mpungu et al., 2012a, Kaharuza et al., 2006).

Routine mental health screening in PHC settings, where most HIV-infected patients are diagnosed and seek regular care, might be a valuable approach to identify both HIV-infected and HIV-uninfected patients who require further mental health assessment. Routine depression screening is recommended for HIV infected patients in high-resource settings and can be an effective way to identify patients at risk for negative outcomes (Shacham et al., 2009, Schumacher et al., 2012, O’Connor et al., 2009). Depressed HIV-infected patients who receive treatment for mental health illness have improved ART adherence and increased quality of life (Yun et al., 2005, Elliott et al., 2002). As interventions to increase access to early ART are scaled up throughout sub-Saharan Africa and universal HIV counseling and testing (HCT) becomes the norm, integration of mental health services and HIV programs could be an important component of ensuring optimal care and treatment utilization for these two highly comorbid conditions (Stein et al., 2005).

Here, we have conducted a validation study of an interviewer-administered brief screening tool for depression, in a high HIV burden, low literacy PHC population in Johannesburg, South Africa. We sought to validate the PHQ-9 as a depression screening tool compared to the internationally validated Mini International Neuropsychiatric Interview (MINI) among patients undergoing routine HCT in a primary care setting. We also sought to provide additional evidence of the utility of the PHQ-9 among HIV-infected people in sub-Saharan Africa.

\section{METHODS}

\section{Ethical approvals}

The Institutional Review Board at the University of North Carolina (No. 12-1730) and the Human Research Ethics Committee at the University of Witwatersrand (No. M120725) approved this study.

\section{Study setting and population}

Witkoppen Health and Welfare Centre (WHWC) is a high-volume primary health care clinic in northern Johannesburg, South Africa that provides comprehensive services predominantly to persons living in densely populated peri-urban formal and informal settlements. At WHWC, every clinic client with an unknown HIV status or with a negative HIV test more than three months old routinely undergoes opt-out HCT.

The study population comprised a randomly selected subset of patients who were undergoing routine HCT at WHWC between September 2012 and April 2013. Participants were eligible for enrollment if they presented at WHWC for any reason, were at least 18 years old, not pregnant by self-report, could communicate in one of 5 common languages used by interviewers (English, isiZulu, isiXhosa, seSotho, seTswana), and were able to provide informed consent. Persons found to be experiencing acute suicidal ideation during the PHQ-9 were excluded and referred for immediate assistance. 


\section{Measures}

PHQ-9-The PHQ-9 is a 9-item depression screening tool that determines the presence and frequency of the 9 core depressive symptoms identified in the DSM-IV over the previous 2 weeks. This tool has been widely utilized in Western settings and more recently in subSaharan Africa (Pence et al., 2012, Monahan et al., 2009, Adewuya et al., 2006, Akena et al., 2013). Scores range from 0-27, with a score of 10 or higher typically used to indicate the presence of a depressive disorder that would benefit from treatment. While the PHQ-9 was developed to be self-administered, interviewer-administration has yielded similar results (Pinto-Meza et al., 2005).

MINI-The MINI International Neuropsychiatric Interview (MINI) is a short, structured diagnostic interview for major psychiatric disorders. The MINI served as the reference standard in this study (Sheehan et al., 1998). The MINI is a reliable and valid diagnostic tool that has been used successfully in South African populations (Myer et al., 2008, Olley et al., 2004). We used the MINI modules for major depressive disorder (MDD), anxiety disorders (generalized anxiety disorder, panic disorder, social anxiety disorder, post-traumatic stress disorder), suicidality, and bipolar disorder.

\section{Study Procedures}

Eligible patients were selected randomly for recruitment each day. Patients were recruited after clinic registration but prior to undergoing HCT. After providing informed consent, the patient completed the screening interview, including the PHQ-9, with a trained layinterviewer. Questions about substance abuse and knowledge of HIV status (from prior testing experiences) were also included in the questionnaire. Socio-demographic information and clinical information was obtained from the patient's WHWC clinic file. Due to low literacy in the study population, the questionnaire was administered by the interviewer and responses were recorded on a paper form. The questionnaire was translated and conducted in 5 common languages (English, isiZulu, isiXhosa, seSotho, seTswana).

After the screening interview, participants immediately completed the MINI interview with a second study team member who was blinded to the results of the PHQ-9. The MINI interview was conducted by health care professionals trained in use of the instrument. The MINI was administered in the same language as the screening interview; an interpreter was used when needed. Translations of the MINI were completed in the same languages used for the screening tools and these standard translations were used when needed.

Study data were collected and managed using Research Electronic Data Capture (REDCap) tools hosted at the University of North Carolina, Chapel Hill (Harris et al., 2009).

\section{Analyses}

A positive screen for probable depression was defined as a score $\geq 10$ on the PHQ-9 (Pence et al., 2012, Adewuya et al., 2006, Akena et al., 2013). Test characteristics including sensitivity, specificity, and categorical likelihood ratios for the PHQ-9 were calculated relative to a diagnosis of a current major depressive episode (MDE) on the MINI. A range of cut-off scores (Data presented for cut-off scores of 8, 10, and 12) was considered for the 
PHQ-9. Categorical likelihood ratios were calculated for the standard scores of $\geq 5$ (mild depression/anxiety), $\geq 10$ (moderate depression/anxiety), $\geq 15$ (moderately severe depression/severe anxiety), and $\geq 20$ (severe depression). Post-test probabilities (analogous to positive predictive values for a dichotomous test) were calculated for a range of prevalence values of depression using categorical likelihood ratios. Receiver operating characteristic (ROC) plots were graphed and the area under the curve (AUC) is reported. Sensitivity analysis was conducted to assess the possible bias in PHQ-9 test performance produced by misclassification of MDE by the MINI. Varying combinations of sensitivity and specificity of the MINI reference standard were considered. In conditional independence scenarios, which did not assume any relationship between a patient's score on the PHQ-9 and their score on the MINI, MINI sensitivity was varied from 0.75 to 1.00 and specificity from 0.97 to 1.00 . In conditional dependence scenarios, it was theorized that patients who underreported depressive symptoms on the PHQ-9 might also underreport on the MINI. For the conditional dependence assessments, a range of reduced sensitivities of the MINI was considered for the population who screened negative on the PHQ-9. Stata version 12 (College Station, TX) was used for all analyses.

\section{RESULTS}

Between September 2012 and April 2013, 397 persons provided informed consent to participate in this study. Participants had a median age of 35 years (IQR: 28-46 years) and most were female $(60 \%)$. About half of the participants were from South Africa $(48 \%)$ and more than a third were from Zimbabwe (37\%). Nearly $60 \%$ were employed and $30 \%$ reported drinking alcohol (Table 1). Of the 397 participants, $257(64.7 \%)$ tested negative for HIV on the enrollment date or within the previous 2 weeks and $113(28.5 \%)$ tested positive at enrollment or were not tested because they told the HIV counselor that they knew their positive status and were enrolled in HIV care at another clinic $(n=9)$. About two-thirds of patients $(65 \%)$ rated their general health status as good, very good, or excellent, while the remainder reported poor or fair health. Compared to patients who were not depressed, patients with depression reported poor or fair health more often $(\mathrm{p}<0.0001)$ and were more likely to be female $(\mathrm{p}=0.06)$ and HIV-infected $(\mathrm{p}=0.08)$. Other demographic characteristics were similar among depressed and not depressed patients. According to the PHQ-9, 44\% of the participants reported no depression (PHQ9 $=0-4), 32 \%$ reported mild depression (PHQ9=5-9), 18\% reported moderate depression (PHQ9=10-14), 5\% reported moderately severe depression (PHQ9=15-19), and 1\% reported very severe depression (PHQ9 $\geq 20$ ).

\section{PHQ-9}

Of the 397 persons completing the MINI, 47 (11.8\%) met the diagnostic criteria for a current MDE on the MINI. Of the 47 patients, 19 (40.4\%) were experiencing a comorbid anxiety disorder and $3(0.76 \%)$ met criteria for bipolar spectrum disorder. The most common comorbid anxiety disorders were generalized anxiety disorder (GAD) and post-traumatic stress disorder (PTSD). Compared to the MINI, the PHQ-9 performed modestly in this population. Of the 47 persons meeting criteria for MDE, 37 had a positive PHQ-9 depression screen with the standard cut-off score of 10 or higher, yielding a sensitivity of 78.7\% (95\% CI: 64.3-89.3) (Table 2). Of the 350 participants who did not meet criteria for 
current major depression on the MINI, 292 had a negative depression screen on the PHQ-9, corresponding to a specificity of $83.4 \%$ (95\% CI: 79.1-87.2). An alternate PHQ-9 cut-off score of 8 in the overall sample yielded a higher sensitivity of $87.2 \%$ (95\% CI: 74.3-95.2) and a lower specificity of 73.4\% (95\% CI: 68.5-78.0). A higher alternate cut-off score of 12 yielded a lower sensitivity of 55.3\% (95\% CI: 40.1-69.8) and a higher specificity of $89.1 \%$ (95\% CI: 85.4-92.2).

In ROC analysis, the PHQ-9 had an area under the curve (AUC) of 0.88 (95\% CI: $0.83-$ 0.92), indicating moderately high accuracy (Figure 1). Likelihood ratios for the commonly used PHQ-9 categories representing mild (5-9), moderate (10-14), moderately severe (1519), and severe (20-27) depression were $0.09,0.50,3.89,6.77$, and 22.3 respectively (Table 3). Post-test probabilities for these categories were calculated for a range of pre-test probability (prevalence) values (Figure 2). At the $11.8 \%$ prevalence of MDE seen in the study population (indicated by vertical line, Figure 2), the post-test probability of depression for a PHQ-9 score between $10-14$ is $34.2 \%$, for a score between $15-20$ it is $47.5 \%$, and for a score higher than 20 it is $75 \%$.

Among HIV-positive participants, $15.0 \%$ ( $\mathrm{n}=17$ ) met the criteria for MDE compared to $8.9 \%$ of the HIV-negative participants. The PHQ-9 performed similarly in the HIV-positive and HIV-negative populations (Table 2). Among the 113 HIV-infected patients, the PHQ-9 yielded a slightly higher sensitivity and a lower specificity compared to the HIV-negative population, although these estimates are imprecise as there were only 17 cases of MDE in the HIV-infected group.

Misclassification of true MDE by the MINI was not likely to have produced substantial bias, as shown by sensitivity analyses. All scenarios where conditional independence was considered suggested that the true values of sensitivity and specificity of the PHQ-9 were underestimated by the observed estimates. Corrected estimates for sensitivity of the PHQ-9 ranged from 0.84 to 0.99 and corrected estimates for specificity of the PHQ-9 ranged from 0.84 to 0.86 . Conditional dependence, assessed by reducing the sensitivity of the MINI for patients screening negative on the PHQ-9, only slightly changed the observed results. Additionally, the performance of the PHQ-9 did not differ according to the language in which the interview was conducted.

\section{DISCUSSION}

In this high HIV burden PHC population in Johannesburg, South Africa, the PHQ-9 showed high accuracy in correctly classifying cases of current MDE (AUC 0.88) relative to the reference standard MINI. At the standard cut-off score of 10, the PHQ-9 had moderately high sensitivity and specificity in the study population. The performance of the PHQ-9 was similar to that from a range of other settings outside of sub-Saharan Africa (Gilbody et al., 2007, Manea et al., 2012). Compared to other studies within sub-Saharan Africa, the PHQ-9 performed slightly worse than it did among university students in Nigeria (Adewuya et al., 2006) or HIV-infected persons in Uganda (Akena et al., 2013), but it performed significantly better in this study than it did among HIV-infected patients in Cameroon (Pence et al., 2012). To our knowledge, ours is the only diagnostic validation study of the PHQ-9 
conducted among a general PHC population in sub-Saharan Africa, and it underscores both the importance of a primary care setting in this region as an access point for identifying depression and as well an accurate tool to do so.

We found an $11.8 \%$ prevalence of MINI-defined current MDE in the overall study sample, higher than previously found among the general population in South Africa. A nationally representative household survey found that $4.9 \%$ of South Africans had suffered from MDE in the previous 12 months, as measured by the World Health Organization's (WHO) Composite International Diagnostic Interview (CIDI) (Tomlinson et al., 2009a). We would expect our estimate to be higher than the prevalence from a household survey as our sample includes chronically ill and disenfranchised patients who are more likely to experience mental illness.

The variation between our prevalence estimate and others from the region may also be explained by other estimates deriving from differing screening instruments, some of which have not been validated against diagnostic tools. Additionally, some other prevalence estimates focus particularly on specific population subsets rather than the general population. For example, among the HIV-infected subset of this population, depression prevalence was $15 \%$, comparable to other prevalence estimates of MDD among HIVinfected African persons in studies using diagnostic tools (range 3-35\%) (Adewuya et al., 2006, Lawler et al., 2011, Nakimuli-Mpungu et al., 2012b, Myer et al., 2008, Akena et al., 2013, Spies et al., 2009). The high prevalence of comorbid anxiety disorders, particularly GAD and PTSD, among depressed patients in this population reiterates the need to assess patients presenting with depressive symptoms for comorbid psychiatric diagnoses, which can lead to increased psychiatric severity and treatment resistance (Kessler et al., 2005, Gaynes et al., 1999).

When evaluating the clinical utility of the PHQ-9 for depression screening and choosing an ideal cut-off score for this setting, we considered the prevalence of depression in the population, the benefits and harms of screening, and the resources available for screening and follow-up. In our study context, a busy PHC clinic in a resource-scarce setting with one part-time mental health professional, patients screened by lay-workers using the PHQ-9 would then be evaluated by a PHC clinician who could confirm that a clinical depression exists and decide whether to begin treatment in the PHC setting or refer to a mental health professional. In this scenario, the categorical likelihood ratios, which capture the magnitude of depression, are particularly useful in prioritizing patients compared to the standard dichotomous cut-off score alone. The standard score of 10 groups together all patients with a score of 10 or higher-so those who have a score of 11 (moderate depression) and those who have a score of 20 (severe depression) are considered the same, discarding valuable information about the degree of illness. In contrast, the categorical likelihood ratios allow the clinician to prioritize patients based on the magnitude of the depression score and the post-test probability of disease for a particular value of the PHQ-9. By multiplying the categorical likelihood ratio for a particular score by the pre-test odds of disease, a post-test odds can be calculated and easily converted to a post-test probability (Sonis, 1999). A patient with a PHQ-9 score of 11 at WHWC has a post-test probability of approximately $34 \%$ of being depressed as compared to a post-test probability of approximately $75 \%$ for a 
patient with a PHQ-9 score of 20. Using the categorical likelihood ratios would allow these two patients with different likelihoods of depression to be prioritized accordingly for the limited mental health resources available at WHWC. The categorical likelihood ratios also allow decision-makers to adjust the pre-test probability value for different groups of patients by taking into account factors such as medical history (e.g. HIV infection status) or laboratory data, rather than only the overall prevalence of depression in the general clinic population. In this more sophisticated approach, one standard cutoff score is not applicable to all patients in a clinic, but rather the cutoff score differs depending on a number of important variables specific to each patient.

In choosing an ideal cut-off score for the PHQ-9, we also considered the relative cost of a false negative versus a false positive result. In our study setting, where many patients were coping with chronic diseases such as HIV, it might be reasonable to consider a false negative, or missing a true case of depression, to be worse than a false positive. Patients with chronic conditions and comorbid depression are at risk for a multitude of negative outcomes including poor adherence to treatment and increased morbidity and mortality (Katon, 2011). Therefore, identifying the maximum number of true depression cases might be considered a priority, especially among HIV infected patients in whom treatment initiation and adherence is a significant concern. This approach would come at the expense of a higher number of false positive screens, creating a higher burden on the clinic to spend time and resources evaluating patients who are not true depression cases. These choices are ultimately dependent on the setting in which the tool is applied and the resources available for followup.

The strengths and limitations of this study should be considered. The cultural construct of depression or anxiety in our study setting is likely to be very different from the Western settings in which the PHQ-9 was first developed. The version of the PHQ-9 used in this study was the same as that used in Cameroon among HIV-infected patients, which had been adapted slightly through focus group feedback in Cameroon (Pence et al., 2012). While we were able to translate the PHQ-9 into local languages, we were unable to conduct additional focus groups or qualitative interviews in our study setting that would have allowed us to further adapt the PHQ-9 for culturally-relevant use in this context and ensure that the tool was well understood by the study population. Although our results did not differ according to the language in which the PHQ-9 was administered, such qualitative research might have increased the diagnostic properties of the PHQ-9 in our study. We would encourage other researchers to conduct preliminary qualitative work when adapting and optimizing screening tools for use outside of the context in which the tool was originally developed and validated.

While the MINI was used as the reference standard in our study, it is imperfect, especially in light of the cultural considerations discussed above. However, the MINI has been validated against other diagnostic interviews, including the CIDI and the Structured Clinical Interview for DSM Disorders (SCID) and has itself been used as a reference standard for the validation of many other psychiatric scales (Sheehan et al., 1998). Misclassification or reference-test bias with use of the MINI is likely to occur to some degree, and will depend partly on the experience level of the interviewer. Given the rigorous DSM-IV criteria utilized in the MINI, we believe that false positives will be rare, although false negatives or missing cases 
of true MDE is possible. This would have biased our measured estimates of PHQ-9 sensitivity and specificity downwards. Our sensitivity analyses were consistent with observed estimates of sensitivity and specificity of the PHQ-9 being underestimated. Given our observed data, a MINI specificity of anything less than 1 would suggest that the reported sensitivity of the PHQ-9 is an underestimate of the true sensitivity. Our data were inconsistent with a MINI specificity less than 0.97 because of the low number of MDE cases among patients screening negative on the PHQ-9. An additional source of bias could have arisen through interviewer-administration of the PHQ-9 as participants may be less likely to report mental health symptoms to an interviewer due to fear of stigmatization. This could lead to conditional dependence through lower sensitivity of the MINI among patients who screen negative on the PHQ-9, but sensitivity analysis showed that this would only slightly affect our observed estimates of PHQ-9 performance.

Mental health screening in this study was conducted among patients prior to undergoing HCT. The advantage to this approach is that it allowed us to evaluate the performance of screening instruments among patients who were HIV-negative as well as the $28.5 \%$ of the study population who tested HIV positive after their participation in this study. Because patients received their HIV test results after depression screening, new knowledge of an HIV diagnosis would not have influenced HIV infected patients to screen positive for depression due to an acute adjustment disorder with a depression reaction. We recognize that the HIVinfected patients in this population are different from those engaging in ongoing HIV care who have been coping with long-term knowledge of HIV status, and that the prevalence of mental illness may differ at various time points in HIV care. Other research on depression and HIV in sub-Saharan Africa has focused mostly on patients who are aware of their HIV status rather than those who are testing for HIV. Our results contribute important information to the field as the mental health of HIV-infected patients prior to HCT has not been evaluated. Identifying patients with underlying depression as early as HCT could help identify patients at risk of defaulting treatment or care early on. Ideally, we would screen patients for mental health illness at several time points in HIV care, if resources for followup exist.

The PHQ-9 performed reasonably well as a screening tool in this high HIV-burden South African clinic population and was easily implemented by lay health workers. Our results provide insight on how we can screen for and prioritize often overlooked and highly prevalent depressive symptoms in low-resource PHC settings in sub-Saharan Africa. Such an intervention might be especially useful for monitoring high-risk subsets of the population such as HIV-infected people at risk for defaulting treatment, although further research will be required to determine how screening for depression can contribute to improved clinical outcomes. This study provides a framework for implementing depression screening programs in resource-scarce sub-Saharan African contexts and establishes the PHQ-9 as a useful screening instrument in these settings.

\section{Acknowledgments}

Role of the funding source This work was supported by the Triangle Community Foundation Gertrude B. Elion Award, National Institute of Mental Health grant 5F30MH096664, and National Institutes of Health Office of the Director, Fogarty International Center, Office of AIDS Research, National Cancer Center, National Heart, Blood, 
and Lung Institute, and the NIH Office of Research for Women's Health through the Fogarty Global Health Fellows Program Consortium comprised of the University of North Carolina, John Hopkins, Morehouse and Tulane (1R25TW009340-01) and the American Recovery and Reinvestment Act.

Financial support for REDCAP was provided by grant UL1RR025747 from the Clinical and Translational Science Award program of the Division of Research Resources, National Institutes of Health.

The authors wish to thank the data collection team-Happiness Ndobe, Mpho Mbulaheni, Nonhlanhla Msimango, Victor Lerato, and Josanne Adam. We thank Dr. Annelies Van Rie for her guidance and support in implementing the study. We are also deeply grateful to the patients and staff at Witkoppen Health and Welfare Center.

\section{References}

ADEWUYA AO, OLA BA, AFOLABI OO. Validity of the patient health questionnaire (PHQ-9) as a screening tool for depression amongst Nigerian university students. J Affect Disord. 2006; 96:8993. [PubMed: 16857265]

AKENA D, JOSKA J, MUSISI S, STEIN DJ. Sensitivity and specificity of a visual depression screening instrument among HIV-positive individuals in Uganda, an area with low literacy. AIDS Behav. 2012a; 16:2399-406. [PubMed: 22810893]

AKENA D, JOSKA J, OBUKU EA, AMOS T, MUSISI S, STEIN DJ. Comparing the accuracy of brief versus long depression screening instruments which have been validated in low and middle income countries: a systematic review. BMC Psychiatry. 2012b; 12:187. [PubMed: 23116126]

AKENA D, JOSKA J, OBUKU EA, STEIN DJ. Sensitivity and specificity of clinician administered screening instruments in detecting depression among HIV-positive individuals in Uganda. AIDS Care. 2013

ANDERSEN LS, GRIMSRUD A, MYER L, WILLIAMS DR, STEIN DJ, SEEDAT S. The psychometric properties of the K10 and K6 scales in screening for mood and anxiety disorders in the South African Stress and Health study. Int J Methods Psychiatr Res. 2011; 20:215-23. [PubMed: 22113964]

BECKER AE, KLEINMAN A. Mental health and the global agenda. N Engl J Med. 2013; 369:66-73. [PubMed: 23822778]

BING EG, BURNAM MA, LONGSHORE D, FLEISHMAN JA, SHERBOURNE CD, LONDON AS, TURNER BJ, EGGAN F, BECKMAN R, VITIELLO B, MORTON SC, ORLANDO M, BOZZETTE SA, ORTIZ-BARRON L, SHAPIRO M. Psychiatric disorders and drug use among human immunodeficiency virus-infected adults in the United States. Arch Gen Psychiatry. 2001; 58:721-8. [PubMed: 11483137]

CHISHINGA N, KINYANDA E, WEISS HA, PATEL V, AYLES H, SEEDAT S. Validation of brief screening tools for depressive and alcohol use disorders among TB and HIV patients in primary care in Zambia. BMC Psychiatry. 2011; 11:75. [PubMed: 21542929]

COLLINS PY, INSEL TR, CHOCKALINGAM A, DAAR A, MADDOX YT. Grand challenges in global mental health: integration in research, policy, and practice. PLoS Med. 2013; 10:e1001434. [PubMed: 23637578]

ELLIOTT AJ, RUSSO J, ROY-BYRNE PP. The effect of changes in depression on health related quality of life (HRQoL) in HIV infection. Gen Hosp Psychiatry. 2002; 24:43-7. [PubMed: 11814533]

FREEMAN M, PATEL V, COLLINS PY, BERTOLOTE J. Integrating mental health in global initiatives for HIV/AIDS. Br J Psychiatry. 2005; 187:1-3. [PubMed: 15994563]

GAYNES BN, MAGRUDER KM, BURNS BJ, WAGNER HR, YARNALL KS, BROADHEAD WE. Does a coexisting anxiety disorder predict persistence of depressive illness in primary care patients with major depression? Gen Hosp Psychiatry. 1999; 21:158-67. [PubMed: 10378109]

GILBODY S, RICHARDS D, BREALEY S, HEWITT C. Screening for depression in medical settings with the Patient Health Questionnaire (PHQ): a diagnostic meta-analysis. J Gen Intern Med. 2007; 22:1596-602. [PubMed: 17874169]

GONZALEZ JS, BATCHELDER AW, PSAROS C, SAFREN SA. Depression and HIV/AIDS treatment nonadherence: a review and meta-analysis. J Acquir Immune Defic Syndr. 2011; 58:181-7. [PubMed: 21857529] 
HARRIS PA, TAYLOR R, THIELKE R, PAYNE J, GONZALEZ N, CONDE JG. Research electronic data capture (REDCap)--a metadata-driven methodology and workflow process for providing translational research informatics support. J Biomed Inform. 2009; 42:377-81. [PubMed: 18929686]

HUGHES J, JELSMA J, MACLEAN E, DARDER M, TINISE X. The health-related quality of life of people living with HIV/AIDS. Disabil Rehabil. 2004; 26:371-6. [PubMed: 15204489]

KAGEE A, MARTIN L. Symptoms of depression and anxiety among a sample of South African patients living with HIV. AIDS Care. 2010; 22:159-65. [PubMed: 20390494]

KAHARUZA FM, BUNNELL R, MOSS S, PURCELL DW, BIKAAKO-KAJURA W, WAMAI N, DOWNING R, SOLBERG P, COUTINHO A, MERMIN J. Depression and CD4 cell count among persons with HIV infection in Uganda. AIDS Behav. 2006; 10:S105-11. [PubMed: 16802195]

KATON WJ. Epidemiology and treatment of depression in patients with chronic medical illness. Dialogues Clin Neurosci. 2011; 13:7-23. [PubMed: 21485743]

KESSLER RC, AGUILAR-GAXIOLA S, ALONSO J, CHATTERJI S, LEE S, ORMEL J, USTUN TB, WANG PS. The global burden of mental disorders: an update from the WHO World Mental Health (WMH) surveys. Epidemiol Psichiatr Soc. 2009; 18:23-33. [PubMed: 19378696]

KESSLER RC, CHIU WT, DEMLER O, MERIKANGAS KR, WALTERS EE. Prevalence, severity, and comorbidity of 12-month DSM-IV disorders in the National Comorbidity Survey Replication. Arch Gen Psychiatry. 2005; 62:617-27. [PubMed: 15939839]

KINYANDA E, HOSKINS S, NAKKU J, NAWAZ S, PATEL V. Prevalence and risk factors of major depressive disorder in HIV/AIDS as seen in semi-urban Entebbe district, Uganda. BMC Psychiatry. 2011; 11:205. [PubMed: 22208452]

LAWLER K, MOSEPELE M, SELOILWE E, RATCLIFFE S, STEELE K, NTHOBATSANG R, STEENHOFF A. Depression among HIV-positive individuals in Botswana: a behavioral surveillance. AIDS Behav. 2011; 15:204-8. [PubMed: 19821023]

LOPES M, OLFSON M, RABKIN J, HASIN DS, ALEGRIA AA, LIN KH, GRANT BF, BLANCO C. Gender, HIV status, and psychiatric disorders: results from the National Epidemiologic Survey on Alcohol and Related Conditions. J Clin Psychiatry. 2012; 73:384-91. [PubMed: 22053858]

MANEA L, GILBODY S, MCMILLAN D. Optimal cut-off score for diagnosing depression with the Patient Health Questionnaire (PHQ-9): a meta-analysis. CMAJ. 2012; 184:E191-6. [PubMed: 22184363]

MONAHAN PO, SHACHAM E, REECE M, KROENKE K, ONG'OR WO, OMOLLO O, YEBEI VN, OJWANG C. Validity/reliability of PHQ-9 and PHQ-2 depression scales among adults living with HIV/AIDS in western Kenya. J Gen Intern Med. 2009; 24:189-97. [PubMed: 19031037]

MYER L, SMIT J, ROUX LL, PARKER S, STEIN DJ, SEEDAT S. Common mental disorders among HIV-infected individuals in South Africa: prevalence, predictors, and validation of brief psychiatric rating scales. AIDS Patient Care STDS. 2008; 22:147-58. [PubMed: 18260806]

NAKIMULI-MPUNGU E, BASS JK, ALEXANDRE P, MILLS EJ, MUSISI S, RAM M, KATABIRA E, NACHEGA J. Depression, Alcohol Use and Adherence to Antiretroviral Therapy in Sub-Saharan Africa: A Systematic Review. AIDS and Behavior. 2012a; 16:2101-2118. [PubMed: 22116638]

NAKIMULI-MPUNGU E, MOJTABAI R, ALEXANDRE PK, KATABIRA E, MUSISI S, NACHEGA JB, BASS JK. Cross-cultural adaptation and validation of the self-reporting questionnaire among HIV+ individuals in a rural ART program in southern Uganda. HIV AIDS (Auckl). 2012b; 4:51-60. [PubMed: 22570575]

NAKIMULI-MPUNGU E, MUSISI S, KATABIRA E, NACHEGA J, BASS J. Prevalence and factors associated with depressive disorders in an $\mathrm{HIV}+$ rural patient population in southern Uganda. $\mathrm{J}$ Affect Disord. 2011; 135:160-7. [PubMed: 21851986]

O'CONNOR EA, WHITLOCK EP, BEIL TL, GAYNES BN. Screening for depression in adult patients in primary care settings: a systematic evidence review. Ann Intern Med. 2009; 151:793803. [PubMed: 19949145]

OLLEY BO, SEEDAT S, NEI DG, STEIN DJ. Predictors of major depression in recently diagnosed patients with HIV/AIDS in South Africa. AIDS Patient Care STDS. 2004; 18:481-7. [PubMed: 15321019] 
OWE-LARSSON B, SALL L, SALAMON E, ALLGULANDER C. HIV infection and psychiatric illness. Afr J Psychiatry (Johannesbg). 2009; 12:115-28. [PubMed: 19582313]

PENCE BW, GAYNES BN, ATASHILI J, O'DONNELL JK, TAYONG G, KATS D, WHETTEN R, WHETTEN K, NJAMNSHI AK, NDUMBE PM. Validity of an interviewer-administered patient health questionnaire-9 to screen for depression in HIV-infected patients in Cameroon. J Affect Disord. 2012

PINTO-MEZA A, SERRANO-BLANCO A, PENARRUBIA MT, BLANCO E, HARO JM. Assessing depression in primary care with the PHQ-9: can it be carried out over the telephone? J Gen Intern Med. 2005; 20:738-42. [PubMed: 16050884]

RAMIREZ-AVILA L, REGAN S, GIDDY J, CHETTY S, ROSS D, KATZ JN, FREEDBERG KA, WALENSKY RP, LOSINA E, BASSETT IV. Depressive Symptoms and Their Impact on Healthseeking Behaviors in Newly-diagnosed HIV-infected Patients in Durban, South Africa. AIDS Behav. 2012

SCHUMACHER JE, MCCULLUMSMITH C, MUGAVERO MJ, INGLE-PANG PE, RAPER JL, WILLIG JH, YOU Z, BATEY DS, CRANE H, LAWRENCE ST, WRIGHT C, TREISMAN G, SAAG MS. Routine Depression Screening in an HIV Clinic Cohort Identifies Patients with Complex Psychiatric Co-morbidities Who Show Significant Response to Treatment. AIDS Behav. 2012

SHACHAM E, NURUTDINOVA D, SATYANARAYANA V, STAMM K, OVERTON ET. Routine screening for depression: identifying a challenge for successful HIV care. AIDS Patient Care STDS. 2009; 23:949-55. [PubMed: 19925308]

SHEEHAN DV, LECRUBIER Y, SHEEHAN KH, AMORIM P, JANAVS J, WEILLER E, HERGUETA T, BAKER R, DUNBAR GC. The Mini-International Neuropsychiatric Interview (M.I.N.I.): the development and validation of a structured diagnostic psychiatric interview for DSM-IV and ICD-10. J Clin Psychiatry. 1998; 59(Suppl 20):22-33. quiz 34-57. [PubMed: 9881538]

SIMONI JM, SAFREN SA, MANHART LE, LYDA K, GROSSMAN CI, RAO D, MIMIAGA MJ, WONG FY, CATZ SL, BLANK MB, DICLEMENTE R, WILSON IB. Challenges in addressing depression in HIV research: assessment, cultural context, and methods. AIDS Behav. 2011; 15:376-88. [PubMed: 21046221]

SMIT J, MYER L, MIDDELKOOP K, SEEDAT S, WOOD R, BEKKER LG, STEIN DJ. Mental health and sexual risk behaviours in a South African township: a community-based cross-sectional study. Public Health. 2006; 120:534-42. [PubMed: 16684549]

SONIS J. How to use and interpret interval likelihood ratios. Fam Med. 1999; 31:432-7. [PubMed: 10367208]

SPIES G, KADER K, KIDD M, SMIT J, MYER L, STEIN DJ, SEEDAT S. Validity of the K-10 in detecting DSMI-V-defined depression and anxiety disorders among HIV-infected individuals. AIDS Care. 2009; 21:1163-8. [PubMed: 20024776]

STEIN DJ, SEEDAT S, EMSLEY RA, OLLEY BO. HIV/AIDS in Africa--a role for the mental health practitioner? S Afr Med J. 2005; 95:167-8. [PubMed: 15832665]

TEGGER MK, CRANE HM, TAPIA KA, ULDALL KK, HOLTE SE, KITAHATA MM. The effect of mental illness, substance use, and treatment for depression on the initiation of highly active antiretroviral therapy among HIV-infected individuals. AIDS Patient Care STDS. 2008; 22:23343. [PubMed: 18290749]

TOMLINSON M, GRIMSRUD AT, STEIN DJ, WILLIAMS DR, MYER L. The epidemiology of major depression in South Africa: results from the South African stress and health study. S Afr Med J. 2009a; 99:367-73. [PubMed: 19588800]

TOMLINSON M, RUDAN I, SAXENA S, SWARTZ L, TSAI AC, PATEL V. Setting priorities for global mental health research. Bull World Health Organ. 2009b; 87:438-46. [PubMed: 19565122]

VOS T, FLAXMAN AD, NAGHAVI M, LOZANO R, MICHAUD C, EZZATI M, SHIBUYA K, SALOMON JA, ABDALLA S, ABOYANS V, ABRAHAM J, ACKERMAN I, AGGARWAL R, AHN SY, ALI MK, ALVARADO M, ANDERSON HR, ANDERSON LM, ANDREWS KG, ATKINSON C, BADDOUR LM, BAHALIM AN, BARKER-COLLO S, BARRERO LH, BARTELS DH, BASANEZ MG, BAXTER A, BELL ML, BENJAMIN EJ, BENNETT D, BERNABE E, BHALLA K, BHANDARI B, BIKBOV B, BIN ABDULHAK A, BIRBECK G, 
BLACK JA, BLENCOWE H, BLORE JD, BLYTH F, BOLLIGER I, BONAVENTURE A, BOUFOUS S, BOURNE R, BOUSSINESQ M, BRAITHWAITE T, BRAYNE C, BRIDGETT L, BROOKER S, BROOKS P, BRUGHA TS, BRYAN-HANCOCK C, BUCELLO C, BUCHBINDER R, BUCKLE G, BUDKE CM, BURCH M, BURNEY P, BURSTEIN R, CALABRIA B, CAMPBELL B, CANTER CE, CARABIN H, CARAPETIS J, CARMONA L, CELLA C, CHARLSON F, CHEN H, CHENG AT, CHOU D, CHUGH SS, COFFENG LE, COLAN SD, COLQUHOUN S, COLSON KE, CONDON J, CONNOR MD, COOPER LT, CORRIERE M, CORTINOVIS M, DE VACCARO KC, COUSER W, COWIE BC, CRIQUI MH, CROSS M, DABHADKAR KC, DAHIYA M, DAHODWALA N, DAMSERE-DERRY J, DANAEI G, DAVIS A, DE LEO D, DEGENHARDT L, DELLAVALLE R, DELOSSANTOS A, DENENBERG J, DERRETT S, DES JARLAIS DC, DHARMARATNE SD, DHERANI M, et al. Years lived with disability (YLDs) for 1160 sequelae of 289 diseases and injuries 1990-2010: a systematic analysis for the Global Burden of Disease Study 2010. Lancet. 2012; 380:2163-96. [PubMed: 23245607]

WANG PS, AGUILAR-GAXIOLA S, ALONSO J, ANGERMEYER MC, BORGES G, BROMET EJ, BRUFFAERTS R, DE GIROLAMO G, DE GRAAF R, GUREJE O, HARO JM, KARAM EG, KESSLER RC, KOVESS V, LANE MC, LEE S, LEVINSON D, ONO Y, PETUKHOVA M, POSADA-VILLA J, SEEDAT S, WELLS JE. Use of mental health services for anxiety, mood, and substance disorders in 17 countries in the WHO world mental health surveys. Lancet. 2007; 370:841-50. [PubMed: 17826169]

YUN LW, MARAVI M, KOBAYASHI JS, BARTON PL, DAVIDSON AJ. Antidepressant treatment improves adherence to antiretroviral therapy among depressed HIV-infected patients. J Acquir Immune Defic Syndr. 2005; 38:432-8. [PubMed: 15764960] 


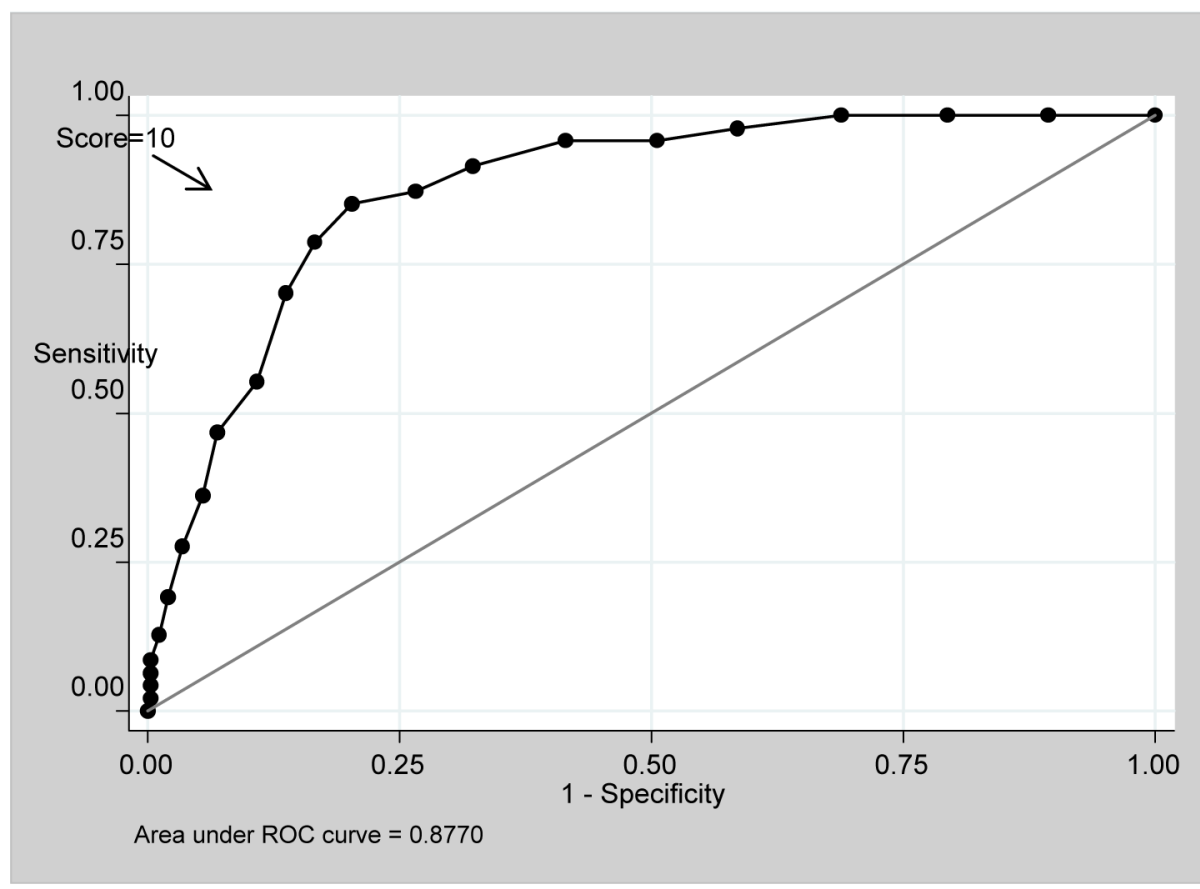

Figure 1.

Receiver operating characteristic (ROC) curve for PHQ-9 


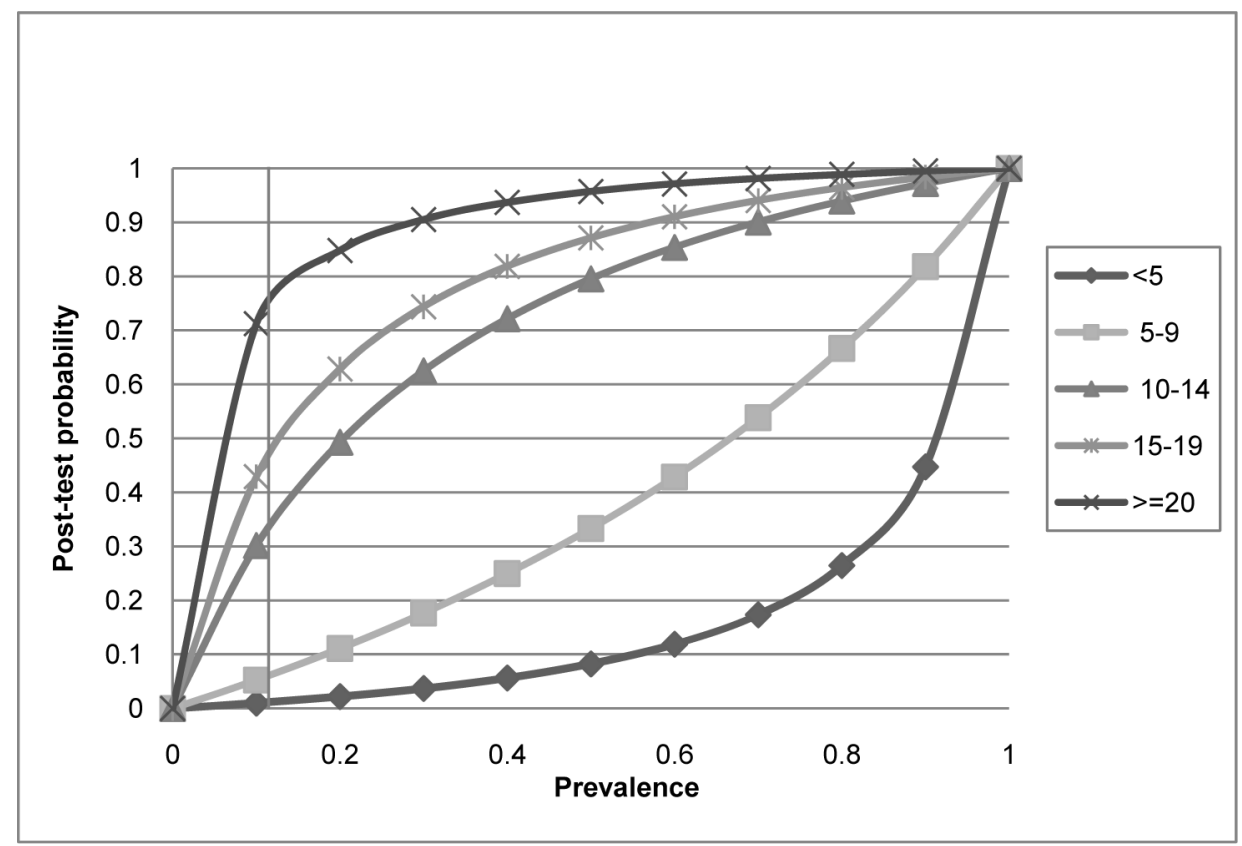

Figure 2.

Post-test probability for varying PHQ-9 categories, based on categorical likelihood ratios. 
Table 1

Characteristics of the study population by depression $(\mathrm{N}=397)$

\begin{tabular}{|c|c|c|c|}
\hline \multirow[t]{2}{*}{ Characteristic } & \multirow{2}{*}{$\begin{array}{c}\text { Total study population }^{*} \\
(\mathrm{n}=397)\end{array}$} & \multicolumn{2}{|c|}{ Depression n (\%) or median (IQR) } \\
\hline & & Yes $(n=47)$ & No $(n=350)$ \\
\hline \multicolumn{4}{|l|}{ Age (years) } \\
\hline$<=25$ & $59(14.9)$ & $4(8.5)$ & $55(15.7)$ \\
\hline $26-35$ & $147(37.0)$ & $20(42.6)$ & $127(36.3)$ \\
\hline $36-45$ & $87(21.9)$ & $10(21.3)$ & $77(22.0)$ \\
\hline $46-55$ & $71(17.9)$ & $10(21.3)$ & $61(17.4)$ \\
\hline$>55$ & $33(8.3)$ & $3(6.4)$ & $30(8.6)$ \\
\hline \multicolumn{4}{|l|}{ Gender } \\
\hline Male & $159(40.1)$ & $13(27.7)$ & $146(41.7)$ \\
\hline Female & $236(59.5)$ & $34(72.3)$ & $202(57.7)$ \\
\hline \multicolumn{4}{|c|}{ Employment status } \\
\hline Employed & $230(63.7)$ & $29(65.9)$ & $201(63.4)$ \\
\hline Unemployed & $131(36.3)$ & $15(34.1)$ & $116(36.6)$ \\
\hline \multicolumn{4}{|l|}{ Country of birth } \\
\hline South Africa & $190(49.9)$ & $27(57.4)$ & $163(48.8)$ \\
\hline Other country & $191(50.1)$ & $20(42.6)$ & $171(51.2)$ \\
\hline \multicolumn{4}{|l|}{ Alcohol use } \\
\hline Any & $118(30.0)$ & $13(28.3)$ & $105(30.2)$ \\
\hline None & $276(70.1)$ & $33(71.7)$ & $243(69.8)$ \\
\hline \multicolumn{4}{|c|}{ Perceived health status } \\
\hline Excellent & $60(15.2)$ & $6(13.0)$ & $54(15.5)$ \\
\hline Very good & $57(14.5)$ & $4(8.7)$ & $53(15.2)$ \\
\hline Good & $139(35.3)$ & $10(21.7)$ & $129(37.1)$ \\
\hline Fair & $79(20.1)$ & $13(28.3)$ & $66(19.0)$ \\
\hline Poor & $59(15.0)$ & $13(28.3)$ & $46(13.2)$ \\
\hline \multicolumn{4}{|l|}{ HIV status } \\
\hline Positive & $113(28.5)$ & $17(36.2)$ & $96(27.4)$ \\
\hline Negative & $257(64.7)$ & $23(48.9)$ & $234(66.9)$ \\
\hline Unknown ${ }^{\dagger}$ & $27(6.8)$ & $7(14.9)$ & $20(5.7)$ \\
\hline
\end{tabular}

* Categories may not sum to the total because of missing data

${ }^{\dagger}$ Twenty seven participants are of unknown HIV status because they were either: 1) found to be either suicidal or mentally distressed during this study so HCT was deferred $(\mathrm{n}=5,1.3 \%) ; 2)$ they refused to test for HIV after undergoing pre-test counseling $(\mathrm{n}=6,1.5 \%)$; or 3$)$ the patient skipped HCT $(n=16,4 \%)$. 


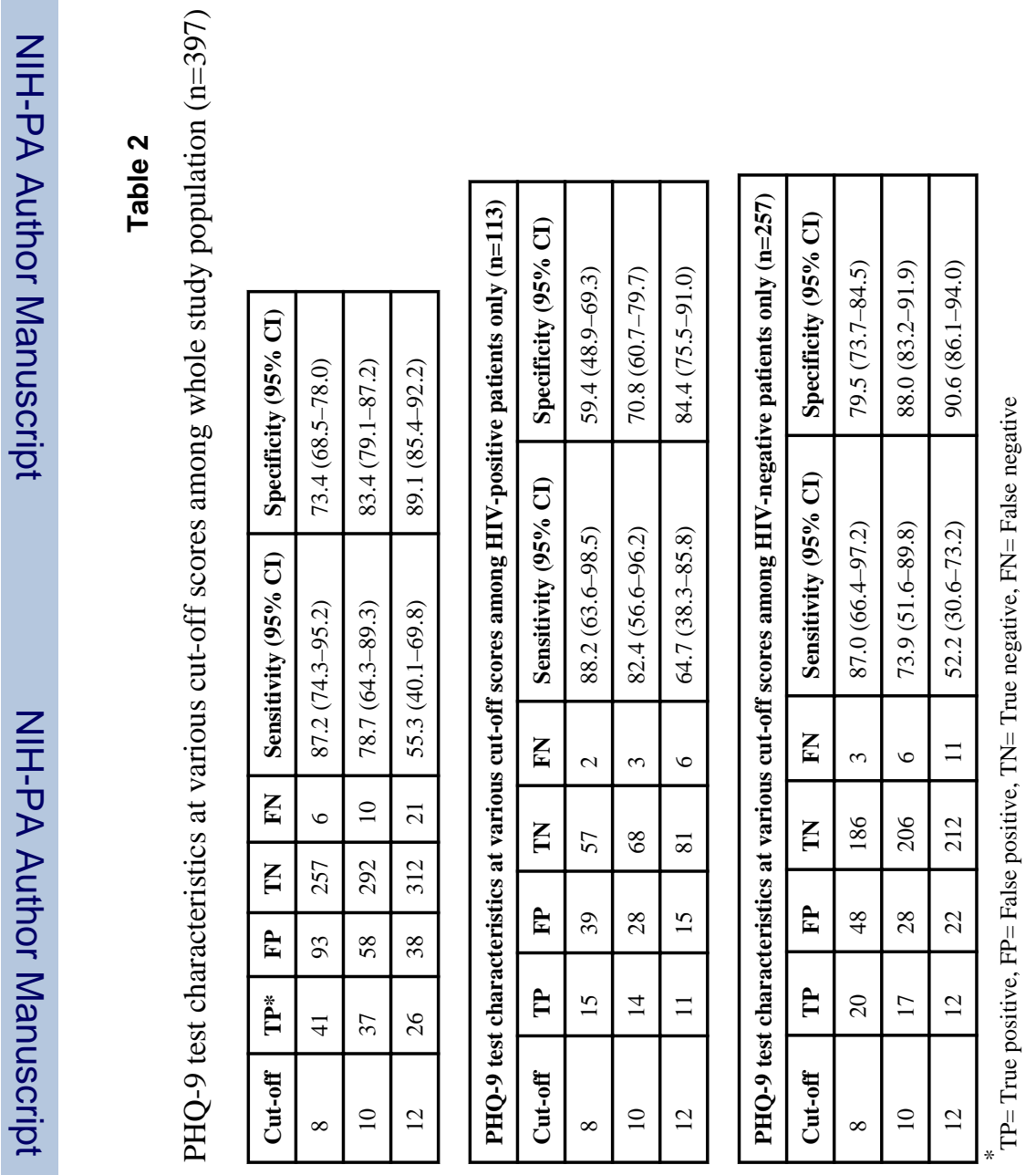


Table 3

Likelihood ratios for commonly used PHQ-9 decision thresholds

\begin{tabular}{|l|l|c|}
\hline Symptom severity & PHQ-9 category & Likelihood ratio \\
\hline No depression & 5 & 0.09 \\
\hline Mild depression & $5-9$ & 0.50 \\
\hline Moderate depression & $10-14$ & 3.89 \\
\hline Moderately severe depression & $15-19$ & 6.77 \\
\hline Severe depression & $20-27$ & 22.3 \\
\hline
\end{tabular}

